\title{
Comparison of mortality in Asbest city and the Sverdlovsk region in the Russian Federation: 1997-2010
}

\author{
E. V. Kovalevskiy ${ }^{1}$, S. J. Schonfeld ${ }^{2}$, E. Feletto ${ }^{2 *}$, M. Moissonnier², S. V. Kashanskiy ${ }^{3}$, I. V. Bukhtiyarov ${ }^{1}$ and J. Schüz ${ }^{2}$
}

\begin{abstract}
Background: The Sverdlovsk region of the Russian Federation is characterised by its abundance of natural resources and industries. Located in this region, Asbest city is situated next to one of the largest open-pit chrysotile asbestos mines currently operational; many city residents are employed in activities related to mining and processing of chrysotile. We compared mortality rates from 1997 to 2010 in Asbest city to the remaining Sverdlovsk region, with additional analyses conducted for site-specific cancer mortality.

Methods: Population and mortality data for Asbest city and Sverdlovsk region were used to estimate crude and age-specific rates by gender for the entire period and for each calendar year. Age-standardized mortality rates were also calculated for the adult population (20+) and Poisson regression was used to estimate standardized mortality ratios, overall and by gender.

Results: During the period of 1997 to 2010, there were similar mortality rates overall in Asbest and the Sverdlovsk region. However, there were higher rates of cancer mortality (18\% males; $21 \%$ females) and digestive diseases ( $21 \%$ males; $40 \%$ females) in Asbest and lower rates of unknown/ill-defined in Asbest (60\% males; $47 \%$ females). Circulatory disease mortality was slightly lower in Asbest. Cancer mortality was higher for men in Asbest from oesophageal, urinary tract and lung cancers compared to the Sverdlovsk region. In women, cancer mortality was higher for women in Asbest from stomach, colon, lung and breast cancers compared to the Sverdlovsk region.
\end{abstract}

Conclusions: This large population-based analysis indicates interesting differences but studies with individual exposure information are needed to understand the underlying factors.

Keywords: Russian Federation, Mortality, Neoplasms, Asbest, Sverdlovsk region

\section{Background}

The Sverdlovsk region, an administrative area of the Russian Federation, is characterised by its abundance of natural resources and different types of industries. Many of these industries are situated in "monotowns" [1], a term referring to towns dominated by a single industry or company centred around these natural resources. Many monotowns in the Sverdlovsk region concentrate on the mining and processing of minerals. Several of those minerals are known to be carcinogenic to humans [2]. Asbest city is a monotown in the region situated

\footnotetext{
* Correspondence: felettoe@fellows.iarc.fr

${ }^{2}$ Section of Environment and Radiation, International Agency for Research on Cancer (IARC), 150 cours Albert Thomas, Lyon 69008, France

Full list of author information is available at the end of the article
}

next to one of the largest open-pit chrysotile asbestos mines currently operational. JSC "Uralasbest", one of the main employers in the city, which produces approximately $20 \%$ of the chrysotile used worldwide. Chrysotile asbestos, like all types of asbestos, is an established carcinogen [3-6]. For this reason, the Sverdlovsk region and Asbest city are compelling geographical areas in which to conduct detailed analyses of mortality, especially cancer.

Previous analyses based on data from 1997 to 2006 compared overall, and a limited number of causespecific, mortality rates in Asbest city with those in the broader Sverdlovsk region [7]. Overall mortality was somewhat higher among females in Asbest than the region but the opposite was seen for males. For both males 
and females, mainly for older ages ( $\geq 59$ years for males and $\geq 54$ years for females), mortality rates were higher in Asbest city compared with the broader Sverdlovsk region for all cancers combined as well as for the groups of respiratory and digestive cancers [7]. Individual cancer sites were not investigated.

In this paper, we expand upon the above-referenced work and include data from 2007 to 2010, thus adding substantially to the number of deaths. The principal objectives were to describe and compare mortality rates in Asbest city with those of the rest of the Sverdlovsk region, with additional analyses conducted for site-specific cancer mortality.

\section{Method}

Population and mortality data for Asbest city and Sverdlovsk region were obtained from the Sverdlovsk regional territorial body of the Federal State Statistic Service of the Russian Federation (FSSS). For purposes of comparing Asbest with the rest of the Sverdlovsk region, we subtracted the Asbest mortality and population data from the full Sverdlovsk region. Hereafter, the "Sverdlovsk region" refers to the region excluding Asbest city. The age distributions of the population (shown for three calendar years in Additional file 1: Figure S1) and total number of deaths (Additional file 2: Figure S2) were similar for Asbest city and the Sverdlovsk region. Mortality data were provided according to the Russian classification system of which different versions were used by the FSSS for 1997-1998 and 1999-2010, with a more detailed breakdown of causes of death provided after 1998. The classification systems were previously described in a study of Russian Federation mortality rates by cause and geographic region [8]. Briefly, the version used in 1997-1998 corresponds to the ninth revision of the International Classification of Diseases (ICD-9) [9] although some individual ICD-9 diagnoses are grouped together in the Russian system. The 1999-2010 version is more detailed and based on the ICD-10 [10]. Site-specific mortality rates for neoplasms were investigated where permitted by both coding systems. It was not within the scope of the study to access death certificates, which would have been useful in identifying cancer types that we problematic to isolate within the coding systems (e.g., mesothelioma).

Crude and age-specific rates per 100,000 persons were calculated by gender and region (Asbest city and Sverdlovsk region). Age-standardized mortality rates (ASRs) per 100,000 persons were estimated for the entire period (1997-2010) and for individual calendar years using the European age standard [11]. The data were restricted to ages $\geq 20$, grouped into 5 -year age groups and weighted as follows for calculation of ASRs: 20-24 (0.10), 25-29 (0.10), 30-34 (0.10), 35-39 (0.10),
40-44 (0.10), 45-49 (0.10), 50-54 (0.10), 55-59 (0.08), 60-64 (0.07), 65-69 (0.06), 70+ (0.10). Poisson regression models were used to estimate standardized mortality ratios (SMRs) and exact $95 \%$ confidence intervals (95\% CIs) overall, by gender and by specific causes of death in Stata version 13.1, using the number of observed deaths in Asbest city as the outcome and the expected number of deaths (calculated by multiplying age-specific death rates in Sverdlovsk oblast (excluding Asbest city) to the Asbest city population) as the log offset. Confidence intervals excluding 1.0 were considered statistically significant. Heterogeneity between gender-specific SMRs was evaluated using likelihood ratio tests (LRT), comparing models with a single SMR estimate to those with gender-specific estimates with $P$ values $<0.05$ considered statistically significant.

\section{Results}

Between 1997 and 2010, there were a total of 16,596 deaths (52\% among males, $48 \%$ among females) in Asbest town and 932, 699 deaths (53\% among males, $47 \%$ among females) in the Sverdlovsk region at age $\geq 20$ years. Table 1 shows the ASRs for the period of 1997 to 2010 for all major categories of mortality in Asbest City and the Sverdlovsk region as well as the SMRs comparing the two populations. Among males and females in both areas, the leading cause of death was from circulatory diseases. This was followed by deaths from cancer and external causes although the relative contribution of these two causes varied between groups; the mortality rate from cancer greatly exceeded that from external causes among females in both areas whereas in the Sverdlovsk region the mortality rate from external causes was markedly higher than that from cancer among males. Among males in Asbest city the mortality rates from cancer and external causes were similar. The fourth leading contributor to death was digestive diseases in all groups except for males in the Sverdlovsk region among whom respiratory deaths exceeded those from the digestive system diseases.

For all persons (i.e., males and females combined), the mortality rates from cancer, endocrine, nutritional and metabolic diseases, digestive diseases, genitourinary diseases and other causes were significantly higher in Asbest than in Sverdlovsk region (SMRs 1.20 to 1.46) although only cancer and digestive disease contributed large numbers of deaths in either area. In contrast, mortality rates from respiratory diseases, mental and behavioural disorders, as well as external and ill-defined and unknown causes of death were significantly lower in Asbest City compared to the Sverdlovsk region (SMRs 0.57 to 0.95). Other causes of death for which SMRs were less than 1 but were not statistically significant include circulatory diseases, infectious and parasitic 
Table 1 Age-standardized rates (ASR) (per 100,000 person-years) and standardized mortality ratios (SMR) for major categories of death for ages 20+ in Asbest city and Sverdlovsk Region by Gender: 1997-2010

\begin{tabular}{|c|c|c|c|c|c|c|c|c|c|c|c|c|}
\hline \multirow[b]{2}{*}{ Cause of death } & \multicolumn{4}{|l|}{ Males } & \multicolumn{4}{|l|}{ Females } & \multicolumn{4}{|l|}{ Persons } \\
\hline & $\mathrm{O}_{\text {Asbest }} \mathrm{b}$ & ASR Asbest & ASR sverdlovsk & SMR $(95 \% \mathrm{Cl})$ & $\mathrm{O}_{\text {Asbest }} \mathrm{b}$ & ASR Asbest & ASR Sverdlovsk & $\operatorname{SMR}(95 \% \mathrm{Cl})$ & $\mathrm{O}_{\text {Asbest }} \mathrm{b}$ & ASR Asbest & ASR sverdlovsk & SMR $(95 \% \mathrm{Cl})$ \\
\hline All-cause mortality & 8661 & 2763.9 & 2801.7 & $0.98(0.96-1.00)$ & 7935 & 1388.5 & 1352.4 & $1.03(1.00-1.05)$ & 16596 & 1947.3 & 1941.6 & $1.00(0.99-1.02)^{c}$ \\
\hline Infectious and parasitic diseases & 220 & 61.9 & 68.2 & $0.90(0.79-1.03)$ & 65 & 14.6 & 14.5 & $1.04(0.81-1.33)$ & 285 & 36.1 & 38.9 & $0.93(0.83-1.05)$ \\
\hline Cancer & 1503 & 496.6 & 416.2 & $1.18(1.12-1.24)$ & 1251 & 229.9 & 192.5 & $1.21(1.14-1.28)$ & 2754 & 322.3 & 270.5 & $1.20(1.15-1.24)$ \\
\hline $\begin{array}{l}\text { Diseases of blood and blood } \\
\text { forming organs }\end{array}$ & 3 & 1.0 & 1.2 & $0.80(0.17-2.34)$ & 4 & 0.8 & 0.9 & $0.84(0.23-2.16)$ & 7 & 0.8 & 1.0 & $0.83(0.33-1.70)$ \\
\hline $\begin{array}{l}\text { Endocrine, nutritional, metabolic } \\
\text { diseases }\end{array}$ & 34 & 10.7 & 7.5 & $1.41(0.98-1.97)$ & 74 & 13.0 & 9.9 & $1.38(1.08-1.73)$ & 108 & 12.5 & 9.2 & $1.39(1.14-1.68)$ \\
\hline Mental and behaviour disorders & 16 & 4.3 & 8.2 & $0.51(0.29-0.83)$ & 8 & 1.6 & 2.2 & $0.75(0.32-1.47)$ & 24 & 3.0 & 5.1 & $0.58(0.37-0.87)$ \\
\hline Diseases of nervous system & 52 & 15.7 & 20.1 & $0.76(0.57-1.00)$ & 57 & 10.8 & 9.3 & $1.26(0.95-1.63)$ & 109 & 13.2 & 14.0 & $0.96(0.79-1.16)^{c}$ \\
\hline Diseases of circulatory system & 4043 & 1354.6 & 1380.5 & $0.98(0.95-1.01)$ & 5059 & 837 & 862.7 & $0.97(0.94-1.00)$ & 9102 & 1042.2 & 1067.2 & $0.98(0.96-1.00)$ \\
\hline Diseases of respiratory system & 359 & 114.3 & 162.3 & $0.71(0.64-0.78)$ & 207 & 37.6 & 36.8 & $1.04(0.90-1.19)$ & 566 & 66.9 & 83.8 & $0.80(0.74-0.87)^{c}$ \\
\hline Diseases of digestive system & 416 & 129.3 & 105.3 & $1.21(1.10-1.33)$ & 386 & 74.9 & 53.3 & $1.40(1.28-1.55)$ & 802 & 96.6 & 74.7 & $1.30(1.21-1.39)^{\mathrm{c}}$ \\
\hline Diseases of genitourinary system & 54 & 17.7 & 16.0 & $1.09(0.82-1.43)$ & 77 & 14.6 & 9.5 & $1.55(1.22-1.94)$ & 131 & 15.5 & 11.7 & $1.33(1.11-1.57)$ \\
\hline All external causes ${ }^{d}$ & 1764 & 497.9 & 527.7 & $0.94(0.90-0.99)$ & 541 & 117.8 & 124.3 & $0.94(0.87-1.03)$ & 2305 & 290.4 & 306.4 & $0.95(0.91-0.99)$ \\
\hline Other causes of death ${ }^{e}$ & 44 & 14.7 & 13.1 & $1.11(0.80-1.49)$ & 161 & 27.5 & 17.4 & $1.61(1.37-1.88)$ & 205 & 23.5 & 16.2 & $1.46(1.27-1.68)^{c}$ \\
\hline III-defined and unknown causes & 153 & 45.1 & 75.3 & $0.60(0.51-0.71)$ & 45 & 8.5 & 18.9 & $0.47(0.34-0.63)$ & 198 & 24.3 & 42.9 & $0.57(0.49-0.65)$ \\
\hline
\end{tabular}

Age-standardized rates for ages 20+ calculated using European standard (5-year age groups 20-69, and 70+)

Number of cases observed in Asbest city

'Male and female SMRs statistically significantly different $(p<0.05)$ based on likelihood ratio test

dFor males and females combined, the largest ASRs for specific external causes were observed for homicides, suicides, other external causes, falls and motor vehicle accidents (traffic and non) in Asbest city and

suicides, injury of undetermined intent, other external causes, unintentional poisoning by alcohol and homicides in Sverdlovsk region

eOther includes categories of pregnancy and childbirth, perinatal, congenital anomalies, benign tumours, otitis media and other diseases of mastoid processes, senility, diseases of skin, diseases of

musculoskeletal system 
diseases, nervous system, and diseases of blood and blood forming organs. Statistically significant differences between male and female SMRs were observed for allcause mortality as well as respiratory, nervous, digestive diseases and the category of "other" causes of death.

The mortality rate from all causes was slightly lower among males in Asbest City then in the Sverdlovsk region (SMR 0.98; $95 \%$ 0.96-1.00) whereas it was marginally elevated for females (SMR 1.03; $95 \%$ 1.00-1.05). For respiratory and nervous system mortality, the rates among males were significantly lower in Asbest than the Sverdlovsk region and this was not observed among females. Although mortality from digestive diseases was consistently higher in Asbest than the Sverdlovsk region, the SMR among females was greater than that for males.

The yearly ASRs for all-cause mortality as well as for selected causes of death are shown by gender and region in Fig. 1. In both regions, mortality rates from these causes were consistently higher among males than females. Consistent with the smaller population size in Asbest city (Additional file 1: Figure S1), there was much greater fluctuation in the mortality rates over time in Asbest city than in Sverdlovsk region. These figures show a decline in the mortality rates from all-cause mortality as well as circulatory diseases, external causes and respiratory diseases among males and females in both Asbest city and Sverdlovsk region after 2005. In contrast, the rates of digestive disease mortality and mortality from ill-defined and unknown causes appeared to be increasing in all groups. These figures further illustrate that the pattern or direction of differences between Asbest city and Sverdlovsk region was generally consistent over time (i.e., consistently higher in Asbest than Sverdlovsk region or vice versa).

Table 2 shows the ASRs and SMRs from 1997 to 2010 for cancer mortality by site. In both regions, the leading causes of cancer mortality were lung cancer in males and breast cancer in females. This was followed by stomach cancer for both males and females. For all persons, the site-specific SMRs were significantly greater than 1 for cancers of the lung, oesophagus, stomach, colon, as well as for the groups of other digestive and urinary tract (SMRs 1.19 to 1.46). Breast cancer mortality was also significantly higher among women in Asbest city than the Sverdlovsk region. No significant differences between Asbest city and Sverdlovsk region were observed for mortality rates of other cancers. The only statistically significant difference between the male and female SMRs was for lung cancer [males - 1.20 (1.101.31); females - $1.76(1.45-2.12)]$ but in both cases the rates were higher in Asbest city than Sverdlovsk region.

\section{Discussion}

We compared mortality rates for the adult population of Asbest city, a monotown in the Sverdlovsk region developed around the mining and processing of chrysotile asbestos, with those for the rest of the region from 1997 to 2010. As observed for the region as a whole, the leading causes of death in Asbest city were from circulatory diseases, cancer, and external causes. This is consistent with previously published data from the Russian Federation $[8,12]$. We also observed a decrease in all-cause mortality, circulatory diseases, external causes and respiratory diseases among males and females in both Asbest city and Sverdlovsk region after 2005; this recent decline in

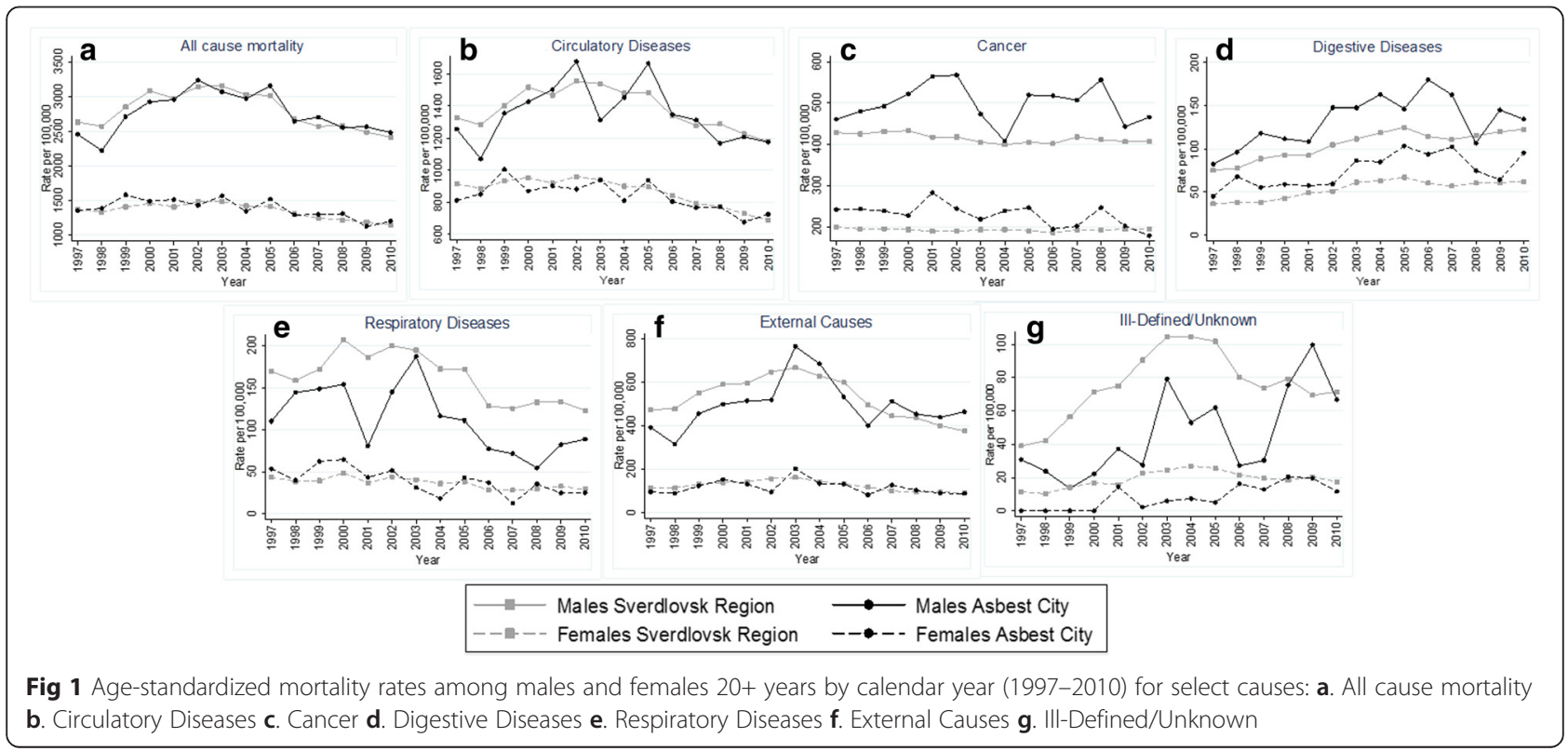


Table 2 Age-standardized rates (per 100,000 person-years) ${ }^{a}$ for cancer and standardized mortality ratios (SMRs), for ages 20+ in Asbest city and Sverdlovsk Region by Gender: 1997-2010

\begin{tabular}{|c|c|c|c|c|c|c|c|c|c|c|c|c|}
\hline \multirow[b]{2}{*}{ Cancer } & \multicolumn{4}{|l|}{ Males } & \multicolumn{4}{|l|}{ Females } & \multicolumn{4}{|l|}{ Persons } \\
\hline & $\mathrm{O}_{\text {Asbest }}{ }^{\mathrm{b}}$ & ASR Asbest & ASR Sverdlovsk $_{\text {. }}$ & SMR $(95 \% \mathrm{Cl})$ & $\mathrm{O}_{\text {Asbest }}{ }^{\mathrm{b}}$ & ASR Asbest & ASR Sverdlovsk & SMR $(95 \% \mathrm{Cl})$ & $\mathrm{O}_{\text {Asbest }}{ }^{b}$ & ASR Asbest & ASR Sverdlovsk & SMR $(95 \% \mathrm{Cl})$ \\
\hline \multicolumn{13}{|l|}{ Respiratory } \\
\hline Larynx & 48 & 15.6 & 12.0 & $1.29(0.95-1.71)$ & 3 & 0.7 & 0.4 & $1.40(0.29-4.08)$ & 51 & 6.1 & 4.7 & $1.30(0.97-1.71)$ \\
\hline Trachea, bronchus, lung & 489 & 161.2 & 132.6 & $1.20(1.10-1.31)$ & 112 & 19.3 & 11.3 & $1.76(1.45-2.12)$ & 601 & 69.9 & 55.1 & $1.29(1.18-1.39)^{c}$ \\
\hline Other respiratory & 13 & 3.8 & 2.3 & $1.78(0.95-3.05)$ & 5 & 0.9 & 0.7 & $1.37(0.44-3.20)$ & 18 & 2.2 & 1.3 & $1.65(0.98-2.61)$ \\
\hline \multicolumn{13}{|l|}{ Digestive } \\
\hline Oesophagus & 51 & 16.9 & 11.3 & $1.46(1.09-1.92)$ & 15 & 2.6 & 1.8 & $1.43(0.80-2.35)$ & 66 & 7.6 & 5.3 & $1.46(1.13-1.85)$ \\
\hline Stomach & 188 & 61.9 & 55.1 & $1.12(0.96-1.29)$ & 165 & 30.1 & 23.2 & $1.28(1.10-1.50)$ & 353 & 41.4 & 34.6 & $1.19(1.07-1.32)$ \\
\hline Small intestine & 4 & 1.3 & 1.3 & $1.02(0.28-2.61)$ & 6 & 1.1 & 0.7 & $1.49(0.55-3.24)$ & 10 & 1.2 & 0.9 & $1.26(0.60-2.31)$ \\
\hline Colon & 86 & 28.7 & 23.6 & $1.24(0.99-1.53)$ & 145 & 25.9 & 18.1 & $1.42(1.20-1.67)$ & 231 & 26.7 & 19.7 & $1.35(1.18-1.53)$ \\
\hline Rectum & 80 & 27.9 & 22.5 & $1.20(0.95-1.49)$ & 73 & 12.7 & 12.6 & $1.04(0.81-1.31)$ & 153 & 17.5 & 15.8 & $1.12(0.95-1.31)$ \\
\hline Other digestive & 145 & 47.2 & 36.5 & $1.29(1.09-1.52)$ & 126 & 22.6 & 20.5 & $1.09(0.91-1.30)$ & 271 & 31.7 & 26.6 & $1.19(1.05-1.34)$ \\
\hline \multicolumn{13}{|l|}{ Hematopoietic } \\
\hline Leukaemia & 33 & 11.4 & 9.1 & $1.18(0.81-1.66)$ & 37 & 7.1 & 5.1 & $1.37(0.97-1.89)$ & 70 & 8.2 & 6.5 & $1.28(0.99-1.62)$ \\
\hline Other hematopoietic & 29 & 9.1 & 8.4 & $1.08(0.72-1.55)$ & 38 & 7.0 & 5.2 & $1.40(0.99-1.93)$ & 67 & 8.0 & 6.4 & $1.24(0.96-1.58)$ \\
\hline \multicolumn{13}{|l|}{ Male genital } \\
\hline Prostate & 67 & 23.4 & 21.5 & $1.09(0.85-1.39)$ & & & & & & & & \\
\hline Other male genital & 7 & 2.3 & 1.5 & $1.47(0.59-3.03)$ & & & & & & & & \\
\hline Breast & & & & & 194 & 37.8 & 32.1 & $1.19(1.03-1.37)$ & & & & \\
\hline \multicolumn{13}{|l|}{ Female genital } \\
\hline Cervix & & & & & 35 & 7.0 & 8.3 & $0.86(0.60-1.20)$ & & & & \\
\hline Uterus & & & & & 51 & 9.7 & 9.0 & $1.05(0.78-1.39)$ & & & & \\
\hline Other female genital & & & & & 65 & 12.5 & 14.5 & $0.86(0.66-1.10)$ & & & & \\
\hline Lip, oral cavity, pharynx & 28 & 9.2 & 13.7 & $0.65(0.43-0.94)$ & 14 & 2.3 & 2.1 & $1.21(0.66-2.03)$ & 42 & 5.0 & 6.5 & $0.77(0.56-1.04)$ \\
\hline Urinary tract & 116 & 38.8 & 29.4 & $1.31(1.08-1.57)$ & 40 & 7.1 & 6.8 & $1.05(0.75-1.43)$ & 156 & 18.2 & 14.7 & $1.24(1.05-1.45)$ \\
\hline Other/unspecified & 118 & 37.7 & 35.1 & $1.07(0.88-1.28)$ & 127 & 23.4 & 20.0 & $1.20(1.00-1.43)$ & 245 & 29.0 & 25.6 & $1.14(1.00-1.29)$ \\
\hline
\end{tabular}

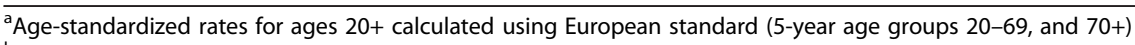

${ }^{\mathrm{b}}$ Number of cases observed in Asbest city

${ }^{c}$ Male and female SMRs statistically significantly different $(p<0.05)$ based on likelihood ratio test 
all-cause mortality and circulatory disease has been reported previously for other parts of the Russian Federation [13-15]. The mortality rates from cancer, endocrine, nutritional and metabolic diseases, digestive diseases, genitourinary diseases and the category of other causes were $20 \%$ to $40 \%$ higher in Asbest city than in the larger Sverdlovsk region whereas rates for respiratory diseases, mental and behavioral disorders, as well as external and ill-defined and unknown causes of death were significantly lower. The leading causes of cancer mortality were similar in the two areas (lung and stomach among men, stomach and breast among women) but for most sites examined, the rates were higher in Asbest city than the Sverdlovsk region.

One of the primary reasons for studying mortality patterns in Asbest is the city's long history of chrysotile asbestos mining and processing activities. Asbestos, including chrysotile and all other forms, is an established human carcinogen [6]; it causes cancers of the lung, ovary, larynx as well as mesothelioma. Positive associations have also been reported for colorectal, stomach and pharyngeal cancers although the evidence is inconclusive [6]. Mortality rates for cancers of the lung, stomach, and colon were statistically significantly higher in Asbest city compared with the wider Sverdlovsk region. In a previous study of lung cancer incidence rates among males in Asbest city and the Sverdlovsk region found consistently elevated rates in Asbest city for the period of 1958 to 2008 [16]. Our findings are consistent with these results. In addition, there were nonsignificant elevated SMRs were also observed for cancers of larynx and rectum. Unlike lung cancer, non-malignant diseases of the respiratory system (composed largely of chronic lower respiratory diseases and pneumonia with few cases of conditions associated with external agents) were lower in Asbest city than in the Sverdlovsk region for males. We were not able to look specifically at pharynx or ovary cancers for the entire period due to the broad grouping in the cause-of-death classification. Furthermore, it was not possible to isolate mortality from mesothelioma as it is not coded separately in either version classification systems used by the FSSS, and there is no dedicated national register for the disease [17]. It has been shown in a review of mesothelioma cases reported from 1881 to 2006 in individual studies in the Russian Federation that over $80 \%$ were of the pleura, with other types being very rare [17], which is similar to reported pleural mesothelioma cases in other countries [18]. As a result, any cases over the period included in our study would likely be included with "other respiratory cancers" which is elevated, but not significantly, in Asbest city compared to the Sverdlovsk region. However, there were only two known cases of malignant pleural mesothelioma in the Sverdlovsk region (personal communication with the Civil Statue Registry Office). Review of original text from death certificates, as would be obtained in studies based on individual rather than population data, would be needed to investigate this cause of death. As part of this register-based study, it was not possible to access the death certificates for other respiratory cancers to determine if they were due to mesothelioma. The increased mortality from several asbestos-related sites may be related to exposures among Asbest city residents, especially occupational exposure as many of the residents were employed in the mines, processing mills as well as manufacturing of other products from chrysotile, but there could be a complex influence of both occupational and environmental exposures present. Other explanations however cannot be dismissed, particularly as there was a general tendency towards higher rates in Asbest city than in the Sverdlovsk region for most cancer sites examined, including those not generally understood to be related to asbestos.

Mortality rates from external causes and digestive diseases, the third and fourth leading causes of death in Asbest city, also differed significantly from the regional rates. There were marginally lower mortality rates from external causes in Asbest city compared to the Sverdlovsk region whereas digestive disease mortality was elevated. Previous studies in the Russian Federation that have focused on mortality trends over time have highlighted the association between patterns of tobacco and alcohol consumption and multiple causes of death including cardiovascular and digestive diseases as well as external causes $[8,12,14,15,19-21]$. We observed somewhat lower mortality rates from circulatory disease and diseases of the respiratory system (non-malignant) in Asbest city compared to the Sverdlovsk region. However, in the absence of individual risk factor information, it is not possible to infer the extent to which differences observed between populations reflect differences in the distribution of risk factors and/or factors related to classification of cause of death. This is an inherent limitation of this type of ecological study.

Notably, we observed lower rates of mortality from illdefined and unknown causes in Asbest city compared with the Sverdlovsk region although they were only 1 and $2 \%$ of deaths respectively for persons age $\geq 20$ years. Figure 1 showed an increase in the mortality rates due to unknown and ill-defined causes over time but the overall low prevalence of deaths that cannot be classified suggests a good quality of the data. The lack of individual information, discussed above, is a general limitation of studies based on population-level mortality data. Studies of this nature, however, benefit from the large number of cases from which to estimate mortality rates, although case numbers were still limited for less common causes of death including several individual cancer sites. 


\section{Conclusion}

In summary, this large population-based study indicates interesting differences between Asbest city and the rest of the Sverdlovsk region for some of the leading causes of mortality. Studies with individual exposure information are needed to understand the factors underlying these differences. One such study is currently underway to better understand the association between chrysotile exposure and the risk of cancer mortality among workers at the mine and processing mills of the JSC Uralasbest [22].

\section{Additional files}

Additional file 1: Figure S1. Age distribution of males (green bars) and females (maroon bars) in Asbest City and Sverdlovsk Region in 1997, 2002, 2006. The different scales reflect the larger population of the Sverdlovsk region compared with Asbest city. (TIF 3500 kb)

Additional file 2: Figure S2. Age distribution of deaths 1997-2010 for males (blue bars) and females (maroon bars) in Asbest city and Sverdlovsk region. The different scales reflect the larger population size and thus absolute number of deaths in Sverdlovsk region compared with Asbest city. (TIF 784 kb)

\section{Competing interest}

The authors declare no conflict of interests, including personal or financial relationships pertinent to the present study of mortality in the city of Asbest and the Sverdlovsk region.

In relation to the Declarations of Interests from the Russian collaborators from SRIOH (Dr Evgeny Kovalevskiy; EK) and the Yekaterinburg Medical Research Center (Dr Sergey Kashansky; SK) for the epidemiological study of workers of the mines and mills in Asbest, the following conflicts of interest were declared: EK and SK reported receiving, on behalf of their institutes and personally through consulting firms, payments from companies to evaluate exposure to asbestos and risk of asbestos-related disease in those workplaces. EK and SK reported attending meetings organized by the International Chrysotile Association and reported that all expenses for attendance were paid by their respective institutes. EK reported participation as an occupational and environmental health expert as part of the delegation of the Russian Ministry of Health at multiple World Health Assembly meetings as well as at the Conference of the Parties to the Basel and Rotterdam Conventions.

\section{Authors' contributions}

EK performed the statistical analysis and drafted the manuscript. EF, MM, SK, IB reviewed manuscript drafts and contributed to the statistical interpretations. SS and JS participated in the design and coordination of the study, reviewed manuscript drafts and contributed to the statistical interpretations. All authors read and approved the final manuscript.

\section{Acknowledgments}

This study is funded by the Ministry of Health of the Russian Federation in the framework of the Federal target programme "National System of Chemical and Biological Safety of the Russian Federation (2009-2014)" under a general framework of action between the Federal state budgetary scientific institution "Scientific Research Institute of Occupational Health" and the International Agency for Research on Cancer (IARC). EF's work is being undertaken during the tenure of an IARC-Australia Postdoctoral Fellowship from the International Agency for Research on Cancer, supported by Cancer Council Australia (CCA).

\section{Author details}

${ }^{1}$ Scientific Research Institute of Occupational Health of the Russian Academy of Medical Sciences, Moscow, Russian Federation. ${ }^{2}$ Section of Environment and Radiation, International Agency for Research on Cancer (IARC), 150 cours Albert Thomas, Lyon 69008, France. ${ }^{3}$ Yekaterinburg Medical Research Center for Prophylaxis and Health Protection in Industrial Workers, Yekaterinburg, Russian Federation.
Received: 23 September 2015 Accepted: 23 February 2016

Published online: 01 March 2016

\section{References}

1. World Bank. The world Bank in Russia: Russian economic report. Washington, DC: World Bank; 2010.

2. Cogliano VJ, Baan R, Straif K, Grosse Y, Lauby-Secretan B, El GF, et al. Preventable exposures associated with human cancers. J Natl Cancer Inst. 2011;103(24):1827-39.

3. IARC Working Group on the Evaluation of Carcinogenic Risks to man. IARC monographs on the evaluation of carcinogenic risk of chemicals to man: some inorganic and organometallic compounds. Vol. 2 ed. Lyon: International Agency for Research on Cancer; 1973.

4. IARC. Working group on the evaluation of carcinogenic risks to humans. IARC monographs on the evaluation of carcinogenic risks to humans: asbestos. Vol. 14 ed. International Agency for Research on Cancer: Lyon; 1977. Available from: PM:863456.

5. IARC Working group on the evaluation of carcinogenic risks to humans. IARC monographs on the evaluation of carcinogenic risk of chemicals to humans: overall evaluations of carcinogenicity: an updating of IARC monographs volumes 1 to 42. Suppl. 7 ed. International Agency for Research on Cancer: Lyon; 1987. Available from: PM:3482203.

6. IARC Working Group on the Evaluation of Carcinogenic Risks to Humans. IARC monographs on the evaluation of carcinogenic risks to humans: A review of human carcinogens. C. Arsenic, metals, fibres, and dusts. Lyon: International Agency for Research on Cancer. Vol 100 C ed; 2012

7. Izmerov NF, Tikhonova Gl, Kovalevskiy EV, Kashanskiy SV, Gorchakova TY, Churanova AN. A comparative analysis of population mortality in the town of Asbest and the Sverdlovsk region. Ukr J Occup Med. 2012; 2012(Supplement):57-62.

8. Men T, Brennan P, Boffetta P, Zaridze D. Russian mortality trends for 19912001: analysis by cause and region. BMJ. 2003;327(7421).

9. World Health Organization. International classification of diseases, 1975 revision (ICD-9). Geneva: World Health Organization; 1977.

10. World Health Organization. International classification of diseases and related health problems, tenth revision (ICD-10). Geneva: World Health Organization; 1992.

11. Doll $R$, Cook P. Summarizing indices for comparison of cancer incidence data. Int J Cancer. 1967;2(3):269-79.

12. Zaridze D, Maximovitch D, Lazarev A, Igitov V, Boroda A, Boreham J, et al. Alcohol poisoning is a main determinant of recent mortality trends in Russia: evidence from a detailed analysis of mortality statistics and autopsies. Int J Epidemiol. 2009;38(1):143-53.

13. Nowbar AN, Howard JP, Finegold JA, Asaria P, Francis DP. 2014 global geographic analysis of mortality from ischaemic heart disease by country, age and income: statistics from World Health Organisation and United Nations. Int J Cardiol. 2014:174(2):293-8.

14. Zaridze D, Brennan P, Boreham J, Boroda A, Karpov R, Lazarev A, et al. Alcohol and cause-specific mortality in Russia: a retrospective casecontrol study of 48557 adult deaths. Lancet. 2009:373(9682):2201-14

15. Zaridze D, Lewington S, Boroda A, Scélo G, Karpov R, Lazarev A, et al. Alcohol and mortality in Russia: prospective observational study of 151000 adults. Lancet. 2014;383(9927):1465-73.

16. Kashanskiy SV, Berzin SA, Kovalevskiy EV. The trend of lung cancer incidence rates for the male population of the town of Asbest, Sverdlovsk region. Ukr J Occup Med. 2012;2012(Supplement):101-4.

17. Kashansky SV. Mesothelioma in Russia: review of 3603 published cases. Journal of US-China Med Sci. 2011;8(2):84-91.

18. Hillerdal G. Malignant mesothelioma 1982: review of 4710 published cases. $\mathrm{Br}$ J Dis Chest. 1983;77(4):321-43

19. Leon DA, Chenet L, Shkolnikov VM, Zakharov S, Shapiro J, Rakhmanova G, et al. Huge variation in Russian mortality rates 1984-94: artefact, alcohol, or what? Lancet. 1997;350(9075):383-8.

20. Plavinski SL, Plavinskaya SI, Klimov AN. Social factors and increase in mortality in Russia in the 1990s: prospective cohort study. BMJ. 2003: 326(7401):1240-2

21. Shkolnikov VM, Mesle F, Leon DA. Premature circulatory disease mortality in Russia: population-and individual-level evidence. In: Weidner 
$G$, editor. Heart disease: environment, stress and gender. Amsterdam: los Press; 2002. p. 39-68.

22. Schuz J, Schonfeld SJ, Kromhout H, Straif K, Kashanskiy SV, Kovalevskiy EV, et al. A retrospective cohort study of cancer mortality in employees of a

Russian chrysotile asbestos mine and mills: study rationale and key features. Cancer Epidemiol. 2013;37(4):440-5.

Submit your next manuscript to BioMed Central and we will help you at every step:

- We accept pre-submission inquiries

- Our selector tool helps you to find the most relevant journal

- We provide round the clock customer support

- Convenient online submission

- Thorough peer review

- Inclusion in PubMed and all major indexing services

- Maximum visibility for your research

Submit your manuscript at www.biomedcentral.com/submit 